\title{
Factors that Influence Satisfaction of People Living with HIV(PLHIV) with Differentiated ART Delivery Models in East Central Uganda: A Cross-Sectional Study
}

Keith Baleeta ( $\sim$ keithbaleeta@gmail.com )

University Research Co.LLC

\section{Augustin Muhwezi}

University Research Co.LLC

Nathan Tumwesigye

University Research Co.LLC

Betty Nsangi Kintu

University Research Co.LLC

\section{Sara Riese}

University Research Co.LLC

\section{Dathan Byonanebye}

Makerere University College of Health Sciences

Martin Mbonye

University Research Co.LLC

Daniel Mwehire

University Research Co.LLC

\section{Robert Iriso}

University Research Co.LLC

\section{Bernard Ayebazibwe}

University Research Co.LLC

\section{Lauren Bailey}

University Research Co.LLC

\section{Deborah Lopez}

University Research Co.LLC

\section{Laura McGough}

University Research Co.LLC

\section{Michael Etukoit}

The AIDS Support Organization

\section{Dyogo Nantamu}

Jinja District Local Government

Jacob Wasswa

University Research Co.LLC

\section{Baker TIbengana}

The AIDS Support Organization

\section{Louisa Nakitende}




\section{Research Article}

Keywords: Differentiated Service Delivery Models (DSDMs), Community Client Led ART Delivery (CCLAD), Community Drug Distribution Points (CDDP), Fast-Track Drug Refill (FTDR), HIV Care, Patient Satisfaction, People Living with HIV/AIDS (PLHIV), East Central Uganda, World Health Organization (WHO), Sub Saharan Africa (SSA).

Posted Date: June 4th, 2021

DOI: https://doi.org/10.21203/rs.3.rs-525866/v1

License: (c) (i) This work is licensed under a Creative Commons Attribution 4.0 International License. Read Full License 


\section{Abstract \\ Background}

The World Health Organization and Uganda Ministry of Health recommend differentiated service delivery models (DSDM) as patient-focussed approaches for delivering antiretroviral therapy for people living with HIV/AIDS (PLHIV) who have undetectable viral loads. We sought to determine the factors significantly associated with patient satisfaction with ART services amongst PLHIV enrolled in DSDMs.

\section{Methods}

This was a cross-sectional study of a random sample of PLHIVs accessing ART within DSDMs at nine facilities in East Central Uganda. Eligible patients were adult PLHIVs active on ART and enrolled in a DSDM (Community Client Led ART Delivery (CCLAD), Community Drug Distribution Points (CDDP) and Fast-Track Drug Refill (FTDR) models) for at-least twelve months. Data was collected over two months (June-July 2019). A validated tool was used to assess PLHIV satisfaction with service delivery in DSD. Logistic regression was used to establish factors associated with patient satisfaction with DSD services.

\section{Results}

Overall out of the 842 participants enrolled onto the study, 530(63.5\%) accessed HIV care through CDDPs, 166(20.1\%) through CCLAD, and 146 (16.3\%) through FTDR DSDMs. Generally, 541 (64.2\%) were satisfied with DSDM services : $78.7 \%$ in CDDP, $42.8 \%$ in CCLAD and $36.3 \%$ in CCLAD. The factors associated with patient satisfaction were being on $\operatorname{CDDP}[\mathrm{aOR}=3.42,95 \% \mathrm{Cl}=2.15-5.44]$ and $\mathrm{FTDR}[\mathrm{aOR}=2.92,95 \% \mathrm{Cl}=1.34-6.31]$ DSDMs relative to CCLAD, greater than three years on DSDM [aOR $=2.32,95 \% \mathrm{Cl}=1.12-4.87$ ], lower transport costs $(<\$ 1.35)$ per clinic visit [aOR $=2.39,95 \% \mathrm{Cl}=1.59-3.60]$ being employed either in agriculture[aOR $=4.41,95 \% \mathrm{Cl}=$ 2.62-7.41] or any other employment sector $[\mathrm{aOR}=4.22,95 \% \mathrm{Cl}=2.46-7.27$ ]relative to being unemployed, participation of a friend/relative $[\mathrm{aOR}=1.79,95 \% \mathrm{Cl}=1.22-2.61]$ and not drinking alcohol $[\mathrm{aOR}=2.33,95 \% \mathrm{Cl}=$ 1.24-4.29].

\section{Conclusions}

The study highlighted that $64.2 \%$ of the patients are satisfied with services in DSDM. Service delivery factors (DSDM model type, time spent in DSDM, and having friend or relative enrolled at the ART point providing social support), social factors (employment, and alcohol consumption), and transport costs were all associated with patient satisfaction with DSDM. Implementers of DSDMs need to further adapt services to address these factors to improve patient satisfaction in DSDMs.

\section{Introduction}

Since 2004, when free anti-retroviral therapy (ART) became available in Sub-Saharan Africa (SSA), remarkable progress has been made, globally, to accelerate ART initiation. There are an estimated 1.3-1.4 million Ugandans living with HIV, and of those, $67 \%$ are on treatment and $59.6 \%$ of adults in the reproductive age bracket (15-64 
years) on ART are virally suppressed are virally suppressed $(1,2)$. More work remains to be done to achieve the UNAIDS fast-track targets to achieve HIV epidemic control which require that $95 \%$ of people living with HIV are aware of their status, $95 \%$ of those aware of their HIV positive status are initiated on treatment, and $95 \%$ of those on treatment achieve and maintain viral suppression by 2030 (3).

Achieving HIV epidemic control requires a massive scale up of ART services. To accelerate the scale up of ART services, the Word Health Organization (WHO) has revised its guidelines, endorsing initiation of ART at all CD4 cell counts. However, the rapid scale up of ART poses many operational challenges for programs in SSA countries including Uganda. First, rapid scale up of ART means that more HIV patients will be initiated on ART, posing system challenges for ART delivery due to infrastructure and health workforce limitations (3). Secondly, to meet these ambitious goals, clients will need to be engaged throughout the HIV care continuum and retained in care for the remaining duration of their life (4-7). Retention in care is the cornerstone to achieving and maintaining viral suppression. Unfortunately, only approximately $75 \%$ of clients initiated on ART are retained in care at 12 months, and retention decreases over time (8). Barriers to retention in care exist at both the individual and health system level. Individual-level barriers include fear of disclosure, distance, and cost of travel, and systems-level barriers include provider attitudes, and clinic issues such as waiting times(9).

Traditional models of facility-based individual HIV care and treatment are not sustainable in the era of ART scale up. Care and treatment services that are responsive to the needs of individual patients are necessary at each step of the HIV cascade (10). To increase the responsiveness of ART programs to individual patient needs, WHO and funding agencies made recommendations for the implementation of differentiated care system models $(3,11)$ .Differentiated service delivery targets the "traditional public health response at a demographic group or geography in a manner that is responsive to the needs of the clients receiving care" (12). In June 2017, Uganda's Ministry of Health released the Implementation Guide for Differentiated Service Delivery Models of HIV Services in Uganda, mandating that all facilities providing ART should implement differentiated service delivery models (13).

The differentiated service delivery models (DSDM) recommended in Uganda for stable patients are (14):

- Fast-track drug refill (FTDR): Clients pick-up drugs from the ART dispensing points without being attended to by a clinician. However, patients are checked in at the facility triage point for quick assessment of urgent care complaints. These clients are assessed by clinicians once every 6 months to review adherence and determine eligibility for continuation in the FTDR program. Data from Uganda show that FTDR models can be costeffective (15), reduce client waiting time, and increase client and provider satisfaction as compared with the current standard of care (16). This model has also been associated with reduction in missed appointments and non-adherence. When implemented in facilities with streamlined patient flow, FTDR models had high rates of 48-week retention and viral suppression among cohorts of adults ( $92 \%$ and $93 \%$ respectively) and children (89\% and 92\% respectively) enrolled in ART programs in Uganda and Kenya $(17,18)$.

- Community Client Led ART Delivery (CCLAD): clients form groups within their communities and rotate drug pick-up form the facility or a community drug distribution point. Patients enrolled in CCLAD DSDM have been shown to achieve high retention in care $(97.7 \%$ at 12 months, $96.0 \%$ at 24 months, $93.4 \%$ at 36 months, and $91.8 \%$ at 48 months) in Mozambique (19)(20), as well as reduce client waiting time, effort, and money spent on monthly trips for ART refill in Lesotho (21).

- Community Drug Distribution Points (CDDP): Clients pick up drugs and receive their clinical evaluations from community outreach points that are closest to them. Evidence from the implementation of the CDDP model in Democratic Republic of Congo (DRC) reveals a high retention in care (89\%) at 12 months in care (22). Evidence 
from Uganda indicates that this approach is effective in achieving viral load suppression in clients (93\% of clients suppressed with a median time on ART of 7 years) (23), as well as reducing loss-to-follow-up as compared to regular facility visits (24). This approach also had lower costs when compared with a mobile ART delivery model using expert clients and when compared with a facility-based nurse-led model (25).

- Facility Based Groups (FBG): When stable clients need peer support, these groups provide such support, as well as drug pick up, as the leader of the group collects the drugs from the pharmacy for the group members and distributes and accounts for them. Evidence from SSA suggests that FBGs improve adherence to antiretroviral therapy, improve retention in care and reduce viral rebound in patients with undetectable viral load (26). In a South African study, facility-based adherence groups had a retained $97 \%$ of the clients in care by 40 months and reduced attrition by $57 \%$ and viral rebound by $67 \%$ (27). In a study in which pre-packaged medicine was given to the group by a lay counselor who conducted symptom screen, FBGs were shown to be cost effective and potentially increase accessibility to ART (28).

In Uganda, community-based differentiated care models are restricted to patients unlikely to have poor outcomes. These include asymptomatic patients with suppressed viral load with relatively long experience on ART. There is evidence that patients accessing ART are increasingly healthy and asymptomatic HIV care for such patients is unlikely to require rigorous care. Such patients will quickly be eligible for community based DSD models. Therefore, the scale-up of DSD must be rapid to meet the expected high number of eligible patients $(29,30)$. As DSDM approaches are still relatively new, there is a need for additional research to deepen the understanding of these approaches and broaden the knowledge base.

Client satisfaction has been shown to be associated with future health care utilization, and as such, plays a part in ensuring client retention along the HIV continuum of care. Data from HIV programs in SSA have reported fair client satisfaction with HIV care services. A study in Zambia reported an average satisfaction of 7.3 on a 10-point scale for HIV services (31). However, there is limited data on client satisfaction within the settings of DSD (31). Two studies from Nigeria, one in an HIV clinic in a tertiary hospital and another in smaller HIV clinics, reported high satisfaction with care in non-DSDM settings (32). A study at a tertiary hospital in Cameroon reported $91 \%$ overall satisfaction with HIV services (33). While all these studies suggest high client satisfaction with HIV care in SSA, client satisfaction with decentralized HIV care in DSD settings has not been described. However, studies from other parts of the world have reported lower client satisfaction with decentralized HIV services (34). Factors associated with client satisfaction are observed at the individual and health system level. Individual level factors associated with client satisfaction with care include education level, expectation, and health status; the health systems factors include accessibility, convenience and availability of services, and provider attitude and respectfulness (35). This study sought to determine the level of satisfaction with care amongst HIV-infected patients receiving ART in DSD models at Nine facilities in the EC region.

\section{Methods}

\section{Study design and setting}

This was a cross-sectional study to determine client satisfaction with care in adult HIV infected patients enrolled in DSD models at nine HIV facilities in six districts in East Central Uganda. The study facilities included two tertiary HIV care facilities that majorly serve urban population (TASO Jinja clinic and Jinja Regional Referral Hospital), and seven relatively high-volume facilities (Health Centre IV and IIIs) that serve rural populations. All study facilities 
provide HIV prevention, testing and treatment services with support from PEPFAR through USAID's Regional Health Integration to Enhance Service (RHITES-EC) project. The facilities had implemented the WHO and Uganda Ministry of health recommendations and had functional DSD models.

Although each of the nine facilities had a relatively large HIV population (> 500 HIV patients active in care), there were critical differences in staffing and facility organization. As of the year 2018, TASO Jinja clinic has the highest (4047) number of patients enrolled in DSD models for greater than 12 months. TASO Jinja clinic is a nongovernment specialized HIV treatment facility that is managed by The AIDS Support Organization, Uganda. Jinja regional referral hospital is a tertiary government hospital with a large, specialized ART clinic with 447 HIV patients enrolled on DSDM for greater than 12 months mostly on CCLAD and FTDR. The remaining facilities are public, with 500-1000 HIV-infected patients active in care and fewer than 100 clients in DSDM for greater than a year.

\section{Study population, participants, and sampling}

The study population was made up of adult HIV-infected patients receiving antiretroviral therapy from one of the three DSD models (CCLAD, CDDP or FTDR) at the above-mentioned nine study facilities within East Central Uganda. To be eligible for the study a participant had to be HIV positive, aged above 18 years of age, enrolled in one of three stable DSD models (CCLAD, CDDP or FTDR) at the nine study facilities within the EC-region for at least 12 months and provided an informed consent. Patients who had known psychiatric illnesses, as well as missing treatment records (particularly VL results within the last 6 months and date of enrolment in DSD model) were excluded from the study.

The Kish Leslie formula below was used to calculate the sample size for this study(36).

$$
\mathbf{n}=\left[\mathrm{z}_{\frac{\alpha}{2}}^{2} * \boldsymbol{\rho}(\mathbf{1}-\boldsymbol{\rho})\right] \div \boldsymbol{\alpha}^{2}
$$

Where $\mathrm{z}$ is the $\mathrm{z}$ value corresponding to the margin of error $(\alpha=0.05)$ and $\mathbb{\nabla}$ is the estimated client satisfaction rate.

A previous cross-sectional study in rural Clinics in South-Western Uganda reported a client satisfaction rate of $58 \%$ in patients attending outpatient HIV services. Assuming power of $80 \%$, and a of 0.05 , the required sample size calculated was 374 participants.

We anticipated a non-response rate of $10 \%$, therefore the adjusted minimum sample size was 415 clients. To mitigate the cluster bias of individuals clustered at facilities, the final sample size was adjusted to 900 individuals. From a master list of all eligible patients (4778), selected from the ART registers from the nine facilities (see Fig. 1). a random but representative sample of 900 patients was selected of whom 842 enrolled in the study. Fifty-eight (58) eligible patients were non-respondents either because they declined to participate or because they could not be readily traced. A summary of the participant recruitment process is provided in Fig. 1.

\section{Data collection}

We used the UgandaEMR database of records of all patients ever registered for care at the study facilities. A data base query was run to generate lists of all patients aged at least 18 years, on ART and participating in DSD models for at least six months. Charts of all prospective participants will be retrieved and assessed for eligibility, data completeness (ART record and documented ART delivery model of any of the three DSDs) and status of engagement determined (loss to follow up versus active in care). For facilities that did not have an electronic patient record system, files of patients enrolled in DSD models were retrieved manually and assessed for eligibility. 
From a line list of all eligible ART patients. A random sample of patients (stratified by key variables including health facility) was selected using Stata 14(StataCorp, College Station, TX, USA).

Eligible patients were contacted to set an appointment for data collection. For patients active in care, appointments were set for the most convenient location for the client, either the next facility appointment, or in the community.

Trained research assistants (RAs) administer the survey tool. A client satisfaction survey form was used to collect data on socio-demographics and client satisfaction domains while a questionnaire was used to abstract data on treatment outcomes including viral suppression from the patient ART card and the ART register.

\section{Development and validation of the patient satisfaction instrument}

A review of patient satisfaction instruments for DSDM for HIV care in program settings did not reveal any previously validated tools. Therefore, an adapted instrument was validated in this research. The initial set of items for the patient satisfaction instrument was generated during a brainstorming session with HIV service delivery experts in Uganda, as well as from qualitative literature around patient experiences with DSDM.

The positive framing of patient satisfaction items can cause bias, therefore items in the adapted instrument had a mix of positive and negative framing. Agree/disagree and yes/no response formats were also limited to reduce acquiescence bias (37).

The initial set of client satisfaction items was pilot tested with a random sample of 30 patients at TASO Jinja and Jinja Regional Referral Hospital. Face validity of the items was assessed using cognitive interviews with a subsample of 10 patients completing the pilot to confirm that the meaning of the questions was clear.

Client satisfaction factors was extracted based on the reliability of the scale. Scale items were assessed for retention based on item-to-total (item to test) correlations, and inter-item (item to rest) correlations. Reliability of the final scale was assessed with Cronbach's alpha coefficient. Corrected item-to-total correlation greater than 0.50 was considered adequate. Scale items with an average item -to total correlation below 0.50 were deleted from the scale. A scale with a Cronbach's alpha coefficient greater than 0.70 was be considered to have an acceptable level of internal reliability(38).

The following items were thus retained with the following item-to-total correlations (see brackets): health worker confidentiality (0.73), psychosocial support received (0.84), time for other priorities $(0.78)$, health cost (0.84) and time spent traveling and waiting to receive ART services (0.84).The resulting final scale of patient satisfaction with five items a Cronbach's alpha of 0.82 was used to measure patient satisfaction with the different service delivery models being tested in this study. Patients were then dichotomized as either satisfied or not satisfied.

\section{Data management and analysis}

Each data collection form was assigned a unique ID. Completed survey questionnaires were reviewed for completeness and entered an electronic online data base daily. Open Data kit (ODK) be used for data entry. Prior to analysis, data was reviewed for completeness. Data was then exported from the study database to Stata 14(StataCorp, College Station, TX, USA) for statistical analysis.

Descriptive statistics were computed and expressed as means ( \pm standard deviations) for normally distributed continuous data or medians (Interquartile range) for continuous but skewed variables. Categorical and ordinal data was summarized as proportions. Client satisfaction was determined as a proportion of patients who reported 
satisfaction for all the validated domains of the (client satisfaction tool health worker confidentiality, psychosocial support received, time for other priorities, health cost and time spent traveling and waiting to receive ART services).

Crude odds ratios (COR) and their $95 \% \mathrm{Cl}$ were computed to determine association between the covariates and client satisfaction. All factors significantly associated with client satisfaction $(p<0.10)$ at the bi-variable analysis were included in the logistic regression model. Regression model analysis was done to determine the suitability of the model. An alpha level of 0.05 was used as a criterion for retaining a variable in the final logistic regression model. The adjusted odds ratio $( \pm 95 \% \mathrm{Cl})$ of covariates associated with client satisfaction was determined using the final logistic regression model.

\section{Results}

\section{Sociodemographic characteristics of the respondents}

A total of 842 respondents were enrolled in this study at nine health care facilities. Among the patient's 588(69.8\%) were females. The median (IQR) age of the participants was $49(42,55)$ years old. The youngest participant was 18years old while the oldest was 82 years old. The study also showed that $486(57.7 \%)$ had at least primary education and 499 (59.3\%) were married. Majority of the patients 720 (85.5\%) of the study participants were living below the poverty line (<\$1.90/day). Furthermore, the study showed that 318 (71\%) of respondents reside less than ten kilometers from their nearest ART distribution point, more than half of the study participants, 457 (55.3\%), had spent more than 10 years in HIV care and 700 (83\%) had spent more than three years in DSDMs', as shown in Table 1. 
Table 1

Characteristics of study participants $(N=842)$

\begin{tabular}{|c|c|c|c|}
\hline Variable Name & Variable Categories & Number & Percent \\
\hline Age & Median (IQR) & $49(42,55)$ & \\
\hline \multirow[t]{2}{*}{ Sex } & Male & 254 & $30.2 \%$ \\
\hline & Female & 588 & $69.8 \%$ \\
\hline \multirow[t]{2}{*}{ Period in HIV care (years) } & $<10$ & 369 & $44.7 \%$ \\
\hline & $\geq 10$ & 457 & $55.3 \%$ \\
\hline \multirow[t]{3}{*}{ Period in DSDM (years) } & $1-2$ & 139 & $16.6 \%$ \\
\hline & $>2-7$ & 441 & $52.6 \%$ \\
\hline & $>7+$ & 259 & $30.9 \%$ \\
\hline \multirow[t]{2}{*}{ Distance $(\mathrm{km})$ to health facility } & $<10$ & 318 & $71.0 \%$ \\
\hline & $\geq 10 \mathrm{~km}$ & 130 & $29.0 \%$ \\
\hline \multirow[t]{3}{*}{ Occupation } & Unemployed & 162 & $19.2 \%$ \\
\hline & Employed in agriculture & 388 & $46.1 \%$ \\
\hline & Employed in non-agriculture sector & 292 & $34.7 \%$ \\
\hline \multirow[t]{2}{*}{ Average daily income } & $<\$ 1.9$ & 720 & $85.5 \%$ \\
\hline & $>\$ 1.9$ & 122 & $14.5 \%$ \\
\hline \multirow[t]{4}{*}{ Education } & None & 99 & $11.8 \%$ \\
\hline & Primary & 486 & $57.7 \%$ \\
\hline & Secondary & 218 & $25.9 \%$ \\
\hline & Tertiary & 39 & $4.6 \%$ \\
\hline \multirow[t]{4}{*}{ Marital status } & Married & 499 & $59.3 \%$ \\
\hline & Separated & 114 & $13.5 \%$ \\
\hline & Never married & 40 & $4.8 \%$ \\
\hline & Widowed & 189 & $22.5 \%$ \\
\hline \multirow[t]{3}{*}{ Drinking alcohol } & Never & 745 & $88.5 \%$ \\
\hline & Once a week & 53 & $6.3 \%$ \\
\hline & At least 2-3 times a week & 44 & $5.2 \%$ \\
\hline \multirow[t]{2}{*}{ Friend/relative at ART delivery point } & Yes & 455 & $54.0 \%$ \\
\hline & No & 387 & $46.0 \%$ \\
\hline
\end{tabular}


Overall, 541 (64.2\%; 95\% confidence intervals,95\%Cl, 514-568) were satisfied with services in DSDM: 78.7\% in CDDP, $42.8 \%$ in CCLAD and $36.3 \%$ in FTDR (Table 2).

Table 2

Level of satisfaction with DSD services by DSD Model

\begin{tabular}{|lllll|}
\hline Variable & Category & $\mathbf{N}$ & $\begin{array}{l}\text { Satisfied } \\
(\mathbf{n = 5 4 1 )}\end{array}$ & $\begin{array}{l}\text { Not satisfied } \\
\mathbf{( n = 3 0 1 )}\end{array}$ \\
\hline Client Satisfaction, DSD Model & CCLAD & 166 & $71(42.8 \%)$ & $95(57.2 \%)$ \\
\hline CDDP & 530 & $417(78.7 \%)$ & $113(21.3 \%)$ \\
\hline FTDR & 146 & $53(36.3 \%)$ & $93(63.7 \%)$ \\
\hline Overall & 842 & $541(64.2 \%)$ & $301(35.8 \%)$ \\
\hline
\end{tabular}

However, As shown in Table 3 satisfaction levels varied greatly for some specific dimensions of quality of HIV services across the three DSDMs. Overall, satisfaction with all domains was lowest in patients enrolled in the facility based DSDM (FTDR) and highest in CDDP.

Table 3

Satisfaction of PLHIV with DSDM by domain contributing most to satisfaction.

\begin{tabular}{|llllll|}
\hline Rank & & CDDP (N= 530) & CCLAD (N 166) & FTDR (N = 146) & Overall (N= 842) \\
\cline { 2 - 6 } & & $\mathbf{n}(\%$ satisfied) & $\mathbf{n ~ ( \% ~ s a t i s f i e d ) ~}$ & n (\% satisfied) & n (\% satisfied) \\
\hline 1 & Confidentiality & $508(95.9 \%)$ & $144(86.8 \%)$ & $84(57.5 \%)$ & $736(87.4 \%)$ \\
\hline 2 & Psychosocial support & $477(90.0 \%)$ & $126(75.9 \%)$ & $82(56.2 \%)$ & $685(81.4 \%)$ \\
\hline 4 & Travel and waiting time & $476(89.8 \%)$ & $116(69.9 \%)$ & $79(54.1 \%)$ & $663(78.5 \%)$ \\
\hline 5 & Health cost & $469(88.5 \%)$ & $115(69.3 \%)$ & $71(48.6 \%)$ & $655(77.8 \%)$ \\
\hline
\end{tabular}

Correlates of patient satisfaction

Multivariate analysis revealed service delivery factors (model type, length of time on DSDM, and having personal support at the ART point), social factors (employment, and alcohol consumption), and transport costs were all significantly associated with patient satisfaction with DSDM $(p<0.05)$ as described in Table 4 .

With regards to socio-demographic factors patients who incurred lower transport costs $(<\$ 1.35)$ per clinic visit $[\mathrm{aOR}=2.39,95 \% \mathrm{Cl}=1.59-3.60]$ had greater than twice the odds of being satisfied relative to those that spent $(>\$$ 1.35) per clinic visit. In addition patients employed either in agriculture [aOR $=4.41,95 \% \mathrm{Cl}=2.62-7.41$ ] or any other employment sector [aOR $=4.22,95 \% \mathrm{Cl}=2.46-7.27$ ] had greater than 4 times the odds of being satisfied relative to patients who were unemployed. It was also noted that patients who did not drink alcohol [aOR $=2.33$, $95 \% \mathrm{Cl}=1.24-4.29]$ had double the odds of being satisfied relative to patients who drank alcohol at least once a week.

With regards to service delivery factors, patients enrolled onto CDDP [aOR $=3.42,95 \% \mathrm{Cl}=2.15-5.44]$ and FTDR $[\mathrm{aOR}=2.92,95 \% \mathrm{Cl}=1.34-6.31]$ had significantly greater odds of patient satisfaction relative to patients on CCLAD 
DSDMs. With regards to length of time on DSDM patients who had greater than three years on DSDM [aOR $=2.32$, $95 \% \mathrm{Cl}=1.12-4.87]$ had more than twice the odds of patient satisfaction relative to patients who had spent less than three years on DSDM. In addition patients who had a friend or relative receiving HIV care from the same ART point $[\mathrm{aOR}=1.79,95 \% \mathrm{Cl}=1.22-2.61]$ had greater than 1.7 times the odds of patient satisfaction relative to patients with no friend or relative at the same ART point. 
Table 4

Multivariate analysis of correlates of client satisfaction with ART services among stable HIV + patients who have been on DSDM for at least 12 months.

\begin{tabular}{|c|c|c|c|c|c|c|}
\hline \multirow[t]{2}{*}{ Variable } & \multicolumn{2}{|c|}{ Patients on DSD } & \multicolumn{2}{|c|}{ Bivariate analysis } & \multicolumn{2}{|c|}{ Multivariate analysis } \\
\hline & $\begin{array}{l}\text { Total No. } \\
\text { of patients } \\
(\mathrm{N}=842)\end{array}$ & $\begin{array}{l}\text { \% Satisfied } \\
(N=541)\end{array}$ & $\begin{array}{l}\mathrm{cOR}[95 \% \\
\mathrm{Cl}]\end{array}$ & $\begin{array}{l}\mathrm{p}- \\
\text { value }\end{array}$ & $\begin{array}{l}\text { aOR [95\% } \\
\mathrm{Cl}]\end{array}$ & p-value \\
\hline \multicolumn{7}{|c|}{ DSD Model } \\
\hline CCLAD & 166 & $71(42.8 \%)$ & Ref & & Ref & \\
\hline CDDP & 530 & $417(78.7 \%)$ & $\begin{array}{l}4.94[3.41- \\
7.16]\end{array}$ & $0.000 *$ & $\begin{array}{l}3.42[2.15- \\
5.44]\end{array}$ & $0.000 * \star$ \\
\hline FTDR & 146 & $53(36.3 \%)$ & $\begin{array}{l}0.76[0.48- \\
1.20]\end{array}$ & 0.244 & $\begin{array}{l}2.92[1.34- \\
6.31]\end{array}$ & $0.006^{\star *}$ \\
\hline \multicolumn{7}{|c|}{ Period on DSDM (In Years) } \\
\hline$<3$ Years & 139 & $46(33.1 \%)$ & Ref & & Ref & \\
\hline $3+$ Years & 700 & $\begin{array}{l}494 \\
(70.6 \%)\end{array}$ & $\begin{array}{l}4.84 \\
{[3.29-} \\
7.15]\end{array}$ & $0.000 *$ & $\begin{array}{l}2.32 \\
{[1.12-} \\
4.87]\end{array}$ & $0.026^{\star *}$ \\
\hline \multicolumn{7}{|c|}{$\begin{array}{l}\text { Prior Missed ART refill } \\
\text { appointment }\end{array}$} \\
\hline Yes & 98 & $31(31.6 \%)$ & Ref & & Ref & \\
\hline No & 744 & $\begin{array}{l}523 \\
(66.8 \%)\end{array}$ & $\begin{array}{l}0.21 \\
{[0.14-} \\
0.33]\end{array}$ & $0.000 *$ & $\begin{array}{l}1.11(0.48- \\
2.56)\end{array}$ & 0.816 \\
\hline \multicolumn{7}{|c|}{ Transport costs } \\
\hline$\geq \$ 1.9$ & 231 & $\begin{array}{l}106 \\
(45.9 \%)\end{array}$ & Ref & & Ref & \\
\hline$<\$ 1.9$ & 611 & $\begin{array}{l}435 \\
(71.2 \%)\end{array}$ & $\begin{array}{l}2.91 \\
{[2.13-} \\
3.98]\end{array}$ & $0.000 *$ & $\begin{array}{l}2.39 \\
{[1.59-} \\
3.60]\end{array}$ & $0.000^{\star *}$ \\
\hline \multicolumn{7}{|c|}{ Age (Years) } \\
\hline$<30$ & 24 & $12(50.0 \%)$ & Ref & & Ref & \\
\hline $30-39$ & 101 & $70(69.3 \%)$ & $\begin{array}{l}2.26 \\
{[0.91-} \\
5.58]\end{array}$ & 0.078 & $\begin{array}{l}0.76 \\
{[0.24-} \\
2.39]\end{array}$ & 0.642 \\
\hline $40-59$ & 560 & $\begin{array}{l}391 \\
(69.8 \%)\end{array}$ & $\begin{array}{l}2.31 \\
{[1.02-} \\
5.25]\end{array}$ & $0.045^{\star}$ & $\begin{array}{l}0.47 \\
{[0.16-} \\
1.36]\end{array}$ & 0.165 \\
\hline $60+$ & 48 & $33(68.8 \%)$ & $\begin{array}{l}2.20 \\
{[0.80-} \\
6.01]\end{array}$ & 0.125 & $\begin{array}{l}0.65 \\
{[0.18-} \\
2.27]\end{array}$ & 0.501 \\
\hline Occupati & & & & & & \\
\hline
\end{tabular}




\begin{tabular}{|c|c|c|c|c|c|c|}
\hline \multirow[t]{2}{*}{ Variable } & \multicolumn{2}{|c|}{ Patients on DSD } & \multicolumn{2}{|c|}{ Bivariate analysis } & \multicolumn{2}{|c|}{ Multivariate analysis } \\
\hline & $\begin{array}{l}\text { Total No. } \\
\text { of patients } \\
(\mathrm{N}=842)\end{array}$ & $\begin{array}{l}\text { \% Satisfied } \\
(N=541)\end{array}$ & $\begin{array}{l}\mathrm{COR}[95 \% \\
\mathrm{Cl}]\end{array}$ & $\begin{array}{l}\mathrm{p}- \\
\text { value }\end{array}$ & $\begin{array}{l}\mathrm{aOR}[95 \% \\
\mathrm{Cl}]\end{array}$ & p-value \\
\hline Unemployed & 162 & $57(35.2 \%)$ & Ref & & Ref & \\
\hline Employed in Agriculture & 388 & $\begin{array}{l}282 \\
(72.7 \%)\end{array}$ & $\begin{array}{l}4.90 \\
{[3.31-} \\
7.25]\end{array}$ & & $\begin{array}{l}4.41 \\
{[2.62-} \\
7.41]\end{array}$ & $0.000^{\star *}$ \\
\hline $\begin{array}{l}\text { Employed in Non- Agriculture } \\
\text { sector }\end{array}$ & 292 & $\begin{array}{l}202 \\
(69.2 \%)\end{array}$ & $\begin{array}{l}4.14[2.75- \\
6.21]\end{array}$ & & $\begin{array}{l}4.22 \\
{[2.46-} \\
7.27]\end{array}$ & $0.000 * \star$ \\
\hline \multicolumn{7}{|l|}{ Alcohol consumption } \\
\hline At-least once a week & 97 & $24(24.7 \%)$ & Ref & & Ref & \\
\hline Does not drink alcohol & 745 & $517(69.4 \%)$ & $\begin{array}{l}6.90[4.24- \\
11.22]\end{array}$ & $0.000 *$ & $\begin{array}{l}2.3[1.24- \\
4.29]\end{array}$ & $0.000 * *$ \\
\hline \multicolumn{7}{|l|}{ Friend/relative at ART Point } \\
\hline No & 387 & $\begin{array}{l}206 \\
(53.2 \%)\end{array}$ & Ref & & Ref & \\
\hline Yes & 455 & $\begin{array}{l}335 \\
(73.6 \%)\end{array}$ & $\begin{array}{l}2.45 \\
{[1.84-} \\
3.27]\end{array}$ & $0.000 *$ & $\begin{array}{l}1.79 \\
{[1.22-} \\
2.61]\end{array}$ & $0.003^{\star \star}$ \\
\hline \multicolumn{7}{|l|}{ Health Facility (type) } \\
\hline $\begin{array}{l}\text { Government Health Facility } \\
\text { (Regional Referral Hospital, } \\
\text { HCIV, HCIII) }\end{array}$ & 127 & $33(25.9 \%)$ & Ref & & Ref & \\
\hline Specialized NGO Clinic & 715 & $\begin{array}{l}508 \\
(71.1 \%)\end{array}$ & $\begin{array}{l}6.99[4.55- \\
10.73]\end{array}$ & & $\begin{array}{l}2.25[0.78- \\
6.49]\end{array}$ & 0.131 \\
\hline
\end{tabular}

\section{Discussion}

The subjective concept of patient satisfaction is a commonly used, critical indicator in evaluation of health care service quality as patients have contributor, target, and reformer roles in quality assurance(39). Patient satisfaction is not only important in evaluating HIV care, but also influences health outcomes including adherence to treatment and retention in care. This study thus sought to fill the gaps in knowledge around patient satisfaction differentiated HIV care for stable patients in East Central Uganda (40).

\section{Levels of satisfaction with DSD services}

In this study, $64.2 \%$ of participants were satisfied with services in the DSDM, which is high. However, a significant proportion (35.8\%) were not fully satisfied with the DSDM services. We found no similar studies found assessing patient satisfaction within DSDM's in sub-Saharan Africa. However, in comparison to studies done assessing patient satisfaction within routine HIV Care, the level of satisfaction in DSD HIV services was within the same range as routine HIV services that extended from $44-95 \%(40,41)$. 


\section{Factors associated with patient satisfaction with DSD services.}

The health service delivery factors associated with patient satisfaction were (model type, length of time on DSDM, and having a friend/relative at accessing ART at the same ART delivery point).

This study found that patients in the CDDP and FTDR DSD models had a significant association with patient satisfaction. Possible explanations for these associations arise may be attributed to the target populations accessing the services. A systematic review of DSD of several DSD studies in sub-Saharan Africa confirms this assertion i.e. the study identified that urban populations preferred facility-based DSD care e.g. FTDR DSDM, while rural populations favoured community-based drug collection i.e. CDDP DSDM (42). Other reasons explaining this association betweens patient satisfaction with the FTDR DSD model is possibly due to significantly decreased waiting times and overall clinic time as documented in one mixed methods study by Alamo et al in Uganda (43). Another cross-sectional study assessing Pharmacist fast-track ART refills in Uganda also documented that reduced waiting time, resulted in high patient satisfaction $(44,45)$.

This study also found a significant association between having a friend or relative receiving antiretroviral therapy (ART) at the same ART service delivery point at with patient satisfaction. Similar findings have been documented in various studies carried out amongst patients receiving routine HIV service deliveries, where having a friend or treatment supporter receiving care from the same ART service delivery point improved peer support, patient satisfaction and conduct of daily life. This was possibly attributed to better communication as well as perceived emotional and psychological supports from friends or relatives accessing care at the same ART service delivery point $(46,47)$.In addition this study also established that time period greater than three years accessing services in a DSD model was significantly associated with patient satisfaction. Similar findings documenting the relationship between patient satisfaction and time spent on DSD have not been documented in peer reviewed journals. These findings however contrast with research among several studies in routine HIV Care done in Canada, Vietnam, Cameroon where no significant association has been documented between duration on antiretroviral therapy or since HIV diagnosis and patient satisfaction. This study thus helps address the knowledge gap on the relationship between HIV treatment duration and patient satisfaction with HIV DSD services $(40,48,49)$.

With regards to socio-demographic factors associated with patient satisfaction included: patients who incurred lower transport costs $(<\$ 1.35)$ per clinic visit, being employed and not drinking alcohol.

In this study lower transport costs $(<\$ 1.35)$ per clinic visit was associated with increased patient satisfaction. These findings are in line with findings from several studies and systematic reviews done from patients on DSD where reduced transport costs is associated with identified as one of the key benefits of participation in especially the community DSD models (CCLAD and CDDP). These reduced transport costs was attributed to reduced frequency of ART clinic visits and jointly contributing to the costs for the member collecting the medication. An additional benefit of reduced transport costs and reduced number of clients was improved patient retention (50, $51)$.

The study found a significant relationship between being employed and patient satisfaction. Previous evidence on this relationship have been mixed, with a statistically significant relationship between patient satisfaction and being employed seen in one study in Cameroon while another study in South Africa did not see a significant relationship $(40,52)$. 
In this study $11.5 \%$ of study participants reported alcohol intake of at least once a week. This is of importance because not drinking alcohol was significantly associated with patient satisfaction for patients on DSD within this study. There are no other documented studies assessing the relationship between patient satisfaction and alcohol consumption with regards to patients in DSD models (17).

Our study has some limitations. We used a cross sectional study design that partly depended on self-reported responses that could be affected by recall bias. Additionally, this study design does not allow for inference for causality. Thirdly, there may have been non-response bias as not all participants invited for the interview turned up for the face-to-face interview potentially those who are dissatisfied with services.

\section{Conclusions}

The study showed that $64.2 \%$ of the patients are satisfied with services in DSDM. This study also revealed substantial dissatisfaction hidden in the global assessment of satisfaction. This study also validated a patient satisfaction tool that had a wide range of patient satisfaction dimensions which were ably reduced to a few critical aspects that align broadly with concepts previously identified in the literature as affecting access to healthcare with adequate validity and reliability, namely: health worker confidentiality, psychosocial support received, time for other priorities, health cost and time spent traveling and waiting to receive ART services. A composite overall client satisfaction variable was developed from these components. Service delivery factors (model type, length of time on DSDM, and having personal support at the ART point), social factors (employment, and alcohol consumption), and transport costs were all associated with patient satisfaction with DSDM. Implementers of DSDMs need to further tailor services to address these factors to improve odds of satisfaction especially in CCLAD and FTDR DSDMs. Such improvements will be critical to further improving HIV patient health outcomes including adherence to ART and retention in HIV care services in Uganda and sub-Saharan Africa.

\section{Abbreviations}

\section{AIDS:}

Acquired Immune Deficiency Syndrome

\section{ART:}

Anti-retroviral therapy

\section{ARVs:}

Anti-retrovirals

\section{CCLAD:}

Community Client-Led ART Delivery

\section{CDDP:}

Community Drug Distribution Points

DSD: 
Differentiated Service Delivery

FBIM:

Facility Based Individual Management

FBG:

Facility Based Group

FTDR:

Fast-Track Drug Refill

MOH:

Ministry of Health

PEPFAR:

The Presidents' Emergency Plan for AIDS Relief

SSA:

Sub-Saharan Africa

WHO:

World Health Organization

\section{Declarations}

Ethics approval and consent to participate: We obtained ethical approval for the study protocol (TASOREC/014/19UG-REC-009) from the accredited TASO REC/IRB and Ethics Committee (UG-REC-009). Permission to conduct research was granted by the Uganda National Council of Science and Technology (UNCST). All interview participants signed a written informed consent form before participating in the study. Principles expressed in the Declaration of Helsinki were followed in the conduct of this study.

Consent for publication: Not Applicable

Availability of data and materials: The datasets used during this study are available from the corresponding author on request.

Competing interests: The authors declare that they have no competing interests.

Funding: The work described in this article was supported by the American people through the United States Agency for International Development (USAID) with funding support from the U.S. President's Emergency Plan for AIDS Relief (PEPFAR). It was implemented under the USAID Regional Health Integration to Enhance Service (RHITES-EC) project, managed by University Research Co. LLC (URC) under the terms of Cooperative Agreement Number AID-617-A-16-00001. The funders had no role in the development or implementation of the study. 
Authors' contributions: All authors significantly contributed to the conceptualization, data collection, data analysis and interpretation, drafting and final approval of the manuscript.

Acknowledgements: We are grateful to all the patients who participated as study participants as well as the clinicians, health service providers and research assistants who supported us during the data collection exercise. We are also thankful for the health facility in-charges and district officials from the 12 districts in East Central Uganda who permitted us to carry-out this research as well as supported us to ensure the research data collection was completed as planned.

\section{References}

1. MOH-Uganda. UGANDA POPULATION-BASED HIV IMPACT ASSESSMENT UPHIA. 2016.

2. UNAIDS. Uganda | UNAIDS [Internet]. 2020 [cited 2020 Mar 24]. Available from: https://www.unaids.org/en/regionscountries/countries/uganda

3. WHO. Consolidated guidelines on the use of antiretroviral drugs for treating and preventing HIV infection [Internet]. 2016 [cited 2021 May 12]. Available from: https://www.paho.org/en/documents/consolidatedguidelines-use-antiretroviral-drugs-treating-and-preventing-hiv-infection

4. Vitoria M, Vella S, Ford N. Scaling up antiretroviral therapy in resource-limited settings: Adapting guidance to meet the challenges [Internet]. Vol. 8, Current Opinion in HIV and AIDS. 2013 [cited 2020 Mar 24]. p. 12-8. Available from: http://www.ncbi.nlm.nih.gov/pubmed/23188179

5. Topp SM, Chipukuma JM. How did rapid scale-up of HIV services impact on workplace and interpersonal trust in Zambian primary health centres: A case-based health systems analysis. BMJ Global Health. 2016 Dec 1;1(4): e000179.

6. Ellman, T; Ford N. Scaling up antiretroviral treatment in resource-poor settings. The lancet HIV [Internet]. 2006 [cited 2020 Mar 24]; Available from: http://www.oecd.org/

7. van Damme W, Kober K, Kegels G. Scaling-up antiretroviral treatment in Southern African countries with human resource shortage: How will health systems adapt? Social Science and Medicine. 2008 May;66(10):2108-21.

8. Fox MP, Rosen S. Retention of adult patients on antiretroviral therapy in low- and middle-income countries: Systematic review and meta-analysis 2008-2013. Journal of Acquired Immune Deficiency Syndromes. 2015 May 1;69(1):98-108.

9. Hall BJ, Sou KL, Beanland R, Lacky M, Tso LS, Ma Q, et al. Barriers and Facilitators to Interventions Improving Retention in HIV Care: A Qualitative Evidence Meta-Synthesis. AIDS and Behavior [Internet]. 2017 Jun 1 [cited 2020 Mar 24];21(6):1755-67. Available from: http://www.ncbi.nlm.nih.gov/pubmed/27582088

10. Grimsrud A, Bygrave H, Doherty M, Ehrenkranz P, Ellman T, Ferris R, et al. Reimagining HIV service delivery: The role of differentiated care from prevention to suppression: The. Vol. 19, Journal of the International AIDS Society. Wiley Blackwell; 2016.

11. Fund G. A Toolkit for Health Facilities: Differentiated Care for HIV and Tuberculosis. 2015.

12. Ehrenkranz PD, Calleja JMG, El-Sadr W, Fakoya AO, Ford N, Grimsrud A, et al. A pragmatic approach to monitor and evaluate implementation and impact of differentiated ART delivery for global and national stakeholders. Vol. 21, Journal of the International AIDS Society. John Wiley and Sons Inc.; 2018.

13. MOH-Uganda. Implementation Guide for Differentiated Service Delivery Models of HIV and TB Services inUganda [Internet]. 2017 [cited 2020 Feb 28]. Available from: 
https://www.differentiatedcare.org/Portals/0/adam/Content/FXBRYsohBEGGGiGnnnli3A/File/Implementation Guide for Differentiated Service Delivery Models of HIV Services in Uganda - 4.9.18.pdf

14. MOH-Uganda. Implementation Guide for Differentiated Service Delivery Models of HIV and TB Services inUganda. 2017.

15. Babigumira JB, Castelnuovo B, Stergachis A, Kiragga A, Shaefer P, Lamorde M, et al. Cost Effectiveness of a Pharmacy-Only Refill Program in a Large Urban HIV/AIDS Clinic in Uganda. van Baal P, editor. PLoS ONE [Internet]. 2011 Mar 28 [cited 2020 Mar 24];6(3): e18193. Available from:

https://dx.plos.org/10.1371/journal.pone.0018193

16. Alamo ST, Wagner GJ, Ouma J, Sunday P, Marie L, Wabwire-Mangen F. Strategies for Optimizing Clinic Efficiency in a Community-Based Antiretroviral Treatment Programme in Uganda. AIDS Behav. 2013;17(1).

17. Obua C, Kayiwa J, Waako P, Tomson G, Balidawa H, Chalker J, et al. Improving adherence to antiretroviral treatment in Uganda with a low-resource facility-based intervention. Global Health Action. 2014;7(1).

18. Kwarisiima D, Kamya MR, Owaraganise A, Mwangwa F, Byonanebye DM, Ayieko J, et al. High rates of viral suppression in adults and children with high CD4+ counts using a streamlined ART delivery model in the SEARCH trial in rural Uganda and Kenya. Journal of the International AIDS Society. 2017 Jul 21;20(Suppl 4):58-67.

19. WHO. Adherence [Internet]. 2003 [cited 2018 Aug 14]. Available from:

http://www.who.int/chp/knowledge/publications/adherence_Section1.pdf

20. Vandendyck M, Motsamai M, Mubanga M, Makhakhe S, Tunggal S, Jonckheree S, et al. Community-Based ART Resulted in Excellent Retention and Can Leverage Community Empowerment in Rural Lesotho, A Mixed Method Study. HIV/AIDS Research and Treatment - Open Journal. 2015 Jun 29;2(2):44-50.

21. Vandendyck M, Motsamai M, Mubanga M, Makhakhe S, Tunggal S, Jonckheree S, et al. Community-Based ART Resulted in Excellent Retention and Can Leverage Community Empowerment in Rural Lesotho, A Mixed Method Study. HIV/AIDS Research and Treatment - Open Journal. 2015 Jun;2(2):44-50.

22. Bemelmans M, Baert S, Goemaere E, Wilkinson L, Vandendyck M, van Cutsem G, et al. Community-supported models of care for people on HIV treatment in sub-Saharan Africa. Tropical Medicine and International Health. 2014;19(8):968-77.

23. Okoboi S, Ding E, Persuad S, Wangisi J, Birungi J, Shurgold S, et al. Community-based ART distribution system can effectively facilitate long-term program retention and low-rates of death and virologic failure in rural Uganda. AIDS Research and Therapy [Internet]. 2015 Nov 12 [cited 2020 Mar 25];12(1):37. Available from: http://www.ncbi.nlm.nih.gov/pubmed/26566390

24. Birungi J, Makabayi R, Kanters S, Luzze C. The AIDS Support Organization (TASO) Community ART delivery models for high patient's retention and good adherence-The AIDS Support Organisation (TASO) experience [Internet]. [cited 2020 Mar 24]. Available from: www.tasouganda.org

25. Vu L, Waliggo S, Zieman B, Jani N, Buzaalirwa L, Okoboi S, et al. Annual cost of antiretroviral therapy among three service delivery models in Uganda. Journal of the International AIDS Society. 2016 Jul 20;19(5Suppl 4).

26. Luque-Fernandez MA, van Cutsem G, Goemaere E, Hilderbrand K, Schomaker M, Mantangana N, et al. Effectiveness of Patient Adherence Groups as a Model of Care for Stable Patients on Antiretroviral Therapy in Khayelitsha, Cape Town, South Africa. PLoS ONE [Internet]. 2013 Feb 13 [cited 2020 Mar 24];8(2): e56088. Available from: http://www.ncbi.nlm.nih.gov/pubmed/23418518 
27. Bemelmans M, Baert S, Goemaere E, Wilkinson L, Vandendyck M, van Cutsem G, et al. Community-supported models of care for people on HIV treatment in sub-Saharan Africa. Tropical Medicine and International Health. 2014;19(8):968-77.

28. Bango F, Ashmore J, Wilkinson L, van Cutsem G, Cleary S. Adherence clubs for long-term provision of antiretroviral therapy: cost-effectiveness and access analysis from Khayelitsha, South Africa. Tropical Medicine and International Health [Internet]. 2016 Sep 1 [cited 2020 Mar 24];21(9):1115-23. Available from: http://www.ncbi.nlm.nih.gov/pubmed/27300077

29. Anderegg N; Panayidou K et al. Global Trends in CD4 Cell Count at the Start of Antiretroviral Therapy: Collaborative Study of Treatment Programs [Internet]. Clinical Infectious Diseases. 2018 [cited 2020 Mar 24]. Available from: https://oxfordjournals.altmetric.com/details/33127776

30. Lubyayi L. Evolution of CD4 Cell Counts over Time for HIV/AIDS Patients on Antiretroviral Therapy (ART) In Mildmay Uganda. Biometrics \& Biostatistics International Journal. 2015 Mar 24;2(2).

31. Dansereau E, Masiye F, Gakidou E, Masters SH, Burstein R, Kumar S. Patient satisfaction and perceived quality of care: Evidence from a cross-sectional national exit survey of HIV and non-HIV service users in Zambia. BMJ Open. 2015 Dec;5(12): e009700.

32. Okafoagu N, Ango JT, Gana G, Kaoje AU, Raji MO, Oche MO, et al. Client's satisfaction with anti-retroviral therapy services in a tertiary hospital in Sokoto, Nigeria. Journal of AIDS and HIV Research. 2013 Sep 30;5(9):328-33.

33. Okoye MO, Ukwe VC, Okoye TC, Adibe MO, Ekwunife OI. Satisfaction of HIV patients with pharmaceutical services in South Eastern Nigerian hospitals. International Journal of Clinical Pharmacy. 2014 Oct 5;36(5):914-21.

34. Wung BA, Peter NF, Atashili J. Clients' satisfaction with HIV treatment services in Bamenda, Cameroon: A crosssectional study. BMC Health Services Research [Internet]. 2016 Jul 19 [cited 2020 Mar 12];16(1):280. Available from: http://bmchealthservres.biomedcentral.com/articles/10.1186/s12913-016-1512-5

35. Tran BX, Nguyen NPT. Patient Satisfaction with HIV/AIDS Care and Treatment in the Decentralization of Services Delivery in Vietnam. Cameron DW, editor. PLoS ONE [Internet]. 2012 Oct 5 [cited 2020 Mar 3]; 7(10): e46680. Available from: https://dx.plos.org/10.1371/journal.pone.0046680

36. Wiegand H. Kish, L.: Survey Sampling. John Wiley \&amp; Sons, Inc., New York, London 1965, IX + 643 S., 31 Abb., 56 Tab., Preis 83 s. Biometrische Zeitschrift [Internet]. 1968 Jan 1 [cited 2020 Mar 24];10(1):88-9. Available from: http://doi.wiley.com/10.1002/bimj.19680100122

37. Dunsch F, Evans DK, Macis M, Wang Q. Bias in patient satisfaction surveys: A threat to measuring healthcare quality. BMJ Global Health. 2018 Mar 1;3(2).

38. Terwee CB, Bot SDM, de Boer MR, van der Windt DAWM, Knol DL, Dekker J, et al. Quality criteria were proposed for measurement properties of health status questionnaires. Journal of Clinical Epidemiology [Internet]. 2007 Jan 24 [cited 2020 Dec 2];60(1):34-42. Available from: https://linkinghub.elsevier.com/retrieve/pii/S0895435606001740

39. Batbaatar E, Dorjdagva J, Luvsannyam A, Savino MM, Amenta P. Determinants of patient satisfaction: A systematic review. Perspectives in Public Health. 2017;137(2):89-101.

40. Wung BA, Peter NF, Atashili J. Clients' satisfaction with HIV treatment services in Bamenda, Cameroon: A crosssectional study. BMC Health Services Research. 2016 Jul;16(1):280. 
41. Atsebeha KG, Chercos DH. High antiretroviral therapy service delivery satisfaction and its' associated factors at Midre-genet hospital; Northwest Tigray, Ethiopia. BMC Health Services Research. 2018;18(1):1-9.

42. Roy M, Bolton Moore C, Sikazwe I, Holmes CB. A Review of Differentiated Service Delivery for HIV Treatment: Effectiveness, Mechanisms, Targeting, and Scale. Current HIV/AIDS Reports. 2019;16(4):324-34.

43. Alamo ST, Wagner GJ, Ouma J, Sunday P, Marie L, Wabwire-Mangen F. Strategies for Optimizing Clinic Efficiency in a Community-Based Antiretroviral Treatment Programme in Uganda. AIDS Behav. 2013;17(1).

44. Nakiwogga-Muwanga A, Katabira E, Sempa J, Kambugu A, Nakibuuka-Lubwama E, Lamorde M, et al. A pharmacy-only refill program at a large HIV clinic in Uganda: Experience and satisfaction of patients. Journal of the International Association of Providers of AIDS Care. 2014;13(3):264-8.

45. Castelnuovo B, Babigumira J, Lamorde M, Muwanga A, Kambugu A, Colebunders R. Improvement of the patient flow in a large urban clinic with high HIV seroprevalence in Kampala, Uganda. International journal of STD \& AIDS [Internet]. 2009 Feb 1 [cited 2020 Feb 28];20(2):123-4. Available from:

http://www.ncbi.nlm.nih.gov/pubmed/19182060

46. Nakigozi G, Makumbi FE, Bwanika JB, Atuyambe L, Reynolds SJ, Kigozi G, et al. Impact of patient-selected care buddies on adherence to HIV care, disease progression, and conduct of daily life among pre-antiretroviral HIVinfected patients in Rakai, Uganda: A randomized controlled trial. Journal of Acquired Immune Deficiency Syndromes. 2015 Sep 1;70(1):75-82.

47. Préau M, Protopopescu C, Raffi F, Rey D, Chêne G, Marcellin F, et al. Satisfaction with care in HIV-infected patients treated with long-term follow-up antiretroviral therapy: The role of social vulnerability. AIDS Care Psychological and Socio-Medical Aspects of AIDS/HIV [Internet]. 2012 Apr 1 [cited 2020 Mar 3];24(4):434-43. Available from: http://www.ncbi.nlm.nih.gov/pubmed/21999644

48. Kielly J, Kelly D v, Asghari S, Burt K, Biggin J. Patient satisfaction with chronic HIV care provided through an innovative pharmacist/nurse-managed clinic and a multidisciplinary clinic.

49. Tran BX, Nguyen NPT. Patient Satisfaction with HIV/AIDS Care and Treatment in the Decentralization of Services Delivery in Vietnam. Cameron DW, editor. PLoS ONE. 2012 Oct;7(10): e46680.

50. Mutasa-Apollo T, Ford N, Wiens M, Socias ME, Negussie E, Wu P, et al. Effect of frequency of clinic visits and medication pick-up on antiretroviral treatment outcomes: A systematic literature review and meta-analysis [Internet]. Vol. 20, Journal of the International AIDS Society. International AIDS Society; 2017 [cited 2020 Mar 13]. p. 21647. Available from: http://doi.wiley.com/10.7448/IAS.20.5.21647

51. Allen O. ART adherence among patients cared in the community client-led ART delivery (CCLAD) - TASO, Uganda experience [Internet]. AIDS 2018 conference. 2018 [cited 2020 Mar 13]. Available from: http://programme.aids2018.org/Abstract/Abstract/10813

52. Chimbindi N, Bärnighausen T, Newell ML. Patient satisfaction with HIV and TB treatment in a public programme in rural KwaZulu-Natal: Evidence from patient-exit interviews [Internet]. Vol. 14, BMC Health Services Research. BioMed Central; 2014 [cited 2020 Mar 13]. p. 32. Available from: https://bmchealthservres.biomedcentral.com/articles/10.1186/1472-6963-14-32

\section{Figures}




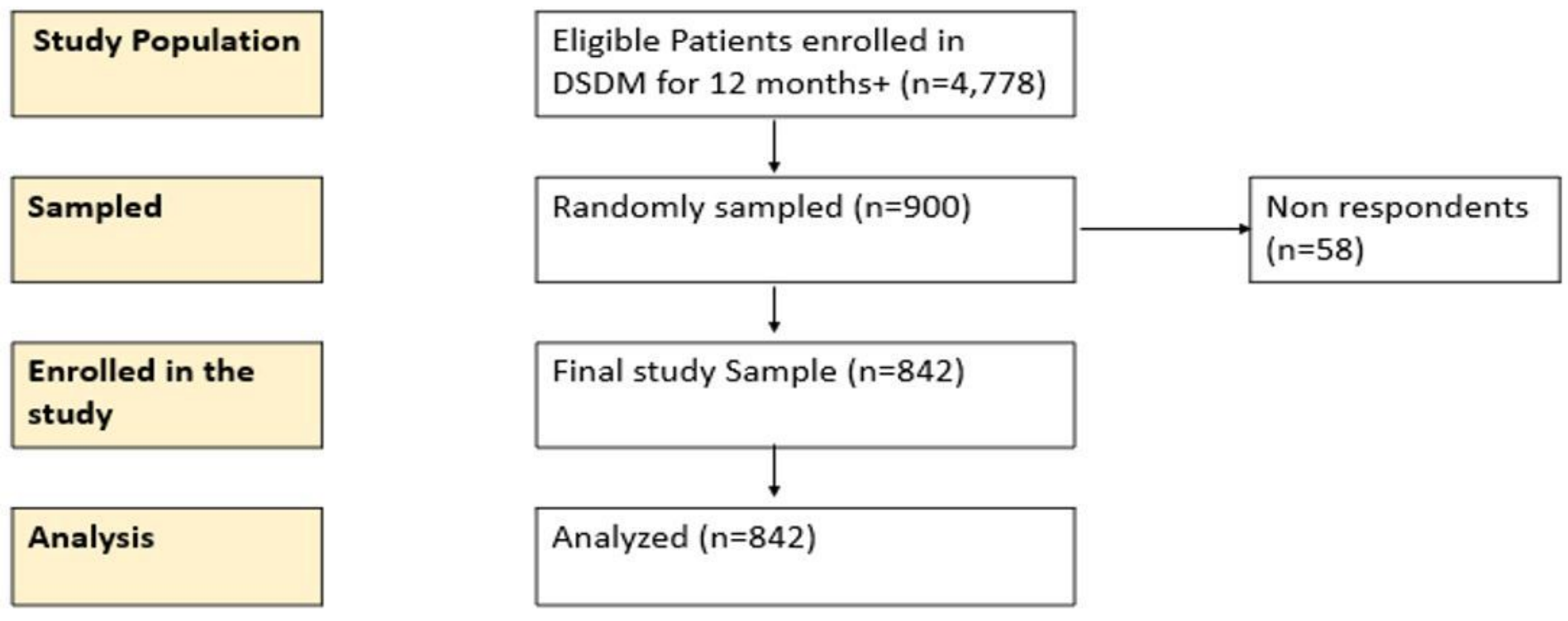

Figure 1

Flowchart illustrating participant recruitment into the study. 